\title{
Why You Really Should Consider Taking on an "IPA"
}

\author{
BY ROBIN D. MUENCH
}

\section{What Motivates This Article?}

From October 2000 through September 2002, I served as scientific program officer on an Intergovernmental Personnel Act (IPA) appointment with the Office of Naval Research, where I worked with the High Latitude Dynamics Program. Detailed half time to the Office of Polar Programs at the National Science Foundation, I effectively held positions at both agencies. This unusual interagency split enabled me to participate in coordinating the funding of Arctic oceanographic research efforts by both agencies and to assist with related program developments internal to each agency. It allowed me to become familiar with the internal priorities and workings of two agencies that have, for the past half-century, provided the bulk of basic research funding for the US oceanographic community. Further, it allowed me to significantly expand the scope of my own research.

My tenure as an "IPA" convinced me, strongly, of the need for active members of the oceanographic research community to participate in agency program management. I hope with this article to interest some Oceanography readers in pursuing such an appointment.
What is an "IPA," and Why Do We Need Them?

Agencies that fund research face an unusual dilemma. On the one hand, these agencies must retain program managers who possess sufficient experience within the agency to make complex programs function. Tenures of years are required to enable program managers to familiarize themselves with the needs and methods appropriate to the agency, and to develop effective management styles. On the other hand, optimal management of a productive and useful research program requires that its managers stay current in their fields of oversight. The catch is that program managers, initially solidly founded in their areas of interest, may not have adequate time to track ongoing developments in these areas. Further, many large programs require expertise in areas outside the manager's own specialty. This is especially germane to oceanography, which has broadened over the past several decades into many highly specialized sub-disciplines, each highly complex in its own right.

Recognition of these issues contributed to Congress enacting the Intergovernmental Personnel Act in 1970 (P.L.
91-648), commonly referred to simply as "IPA." It became possible under this act for scientific researchers to spend time "on loan" from their home organizations to government agencies. Researchers could now spend one to two years working intensively with career agency program managers. Information on new research developments could be made available directly to program management teams in their quest for the information that is crucial to effective research management. As compensation for this period of "civil service," the IPA appointee received detailed knowledge of the inner workings of the agency, and its goals and priorities, and a level of exposure to the broader scientific community that would be difficult, if not impossible, to attain in any other fashion. Two agencies that have made extensive use of the IPA, and that have been strongly and positively impacted by it, have been the Office of Naval Research and the National Science Foundation.

Robin D. Muench (rmuench@esr.org) is Senior Scientist, Earth and Space Research, Seattle, WA, USA. 


\section{What Does Being an IPA}

\section{Appointee Entail?}

An IPA appointee is normally associated with one or more programs within an agency and works primarily with the managers associated with those programs. Specific tasks depend on program needs; most appointments involve evaluating research proposals and assisting in program goal and priority development, and program implementation. In order to function within an agency context, an appointee needs to become acquainted with both overarching agency goals and with routine management procedures. Active researchers will typically have acquired much of this knowledge through dealing with agencies, both in requesting research funding and in participating in agency functions such as review panels. Even given prior acquaintance, an appointee stands to gain a wealth of new knowledge on underlying agency objectives and procedures. Further, the appointee will also gain an enhanced understanding of areas outside of their own specialty. For example, I started my IPA as a broadly based, high-latitude physical oceanographer and departed this appointment having acquired a strong mandate to focus on ocean mixing, (albeit with an emphasis on high-latitude oceans). This was made possible through the contacts I made during my appointment, the use of conferences for networking and planning, and strong encouragement from others within the agencies.

Different agencies can and do collaborate in funding research programs, especially large programs that may cover a number of areas within a discipline. Much of this collaboration goes on behind the scenes and may not be espe- cially well known outside the involved agency personnel. An IPA appointee will be exposed to, and will very likely assist in structuring, such collaborative efforts. During my IPA, I participated in planning workshops involving other agencies such as NASA, NOAA, and the US Department of Agriculture, and acquired considerable background on the goals and concerns of these and other agencies.

Finally, an IPA appointee interacts extensively with the scientific community through personal, phone, and email communication and by attending scientific conferences and workshops. Depending upon the agency, considerable travel may be required to attend national and international conferences

\section{Information for the Intrigued} By taking on an IPA appointment, you can provide a service to a participating government agency and can acquire significant benefits for yourself and your home institution. Prior planning can help to maximize both the service provided and the benefits returned.

The timing of an IPA relative to one's current research activities is important because the appointment will strongly impact the time available for research. IPA appointments come in one-year increments and usually extend over two such increments. There are reasons for this time scale: it takes about one year to learn an agency's workings sufficiently to have an impact; however, if the ap-

\section{Agencies that fund research face an unusual dilemma. On the one hand, these agencies must retain program managers who possess sufficient experience within the agency to make complex programs function... On the other hand, optimal management of a productive and useful research program requires that its}

managers stay current in their fields of oversight.

and to participate in site visits to different institutions. This interaction with the scientific community is essential for identifying promising new research directions and for evaluating progress of ongoing research. The contacts developed through such interactions are of major potential benefit to the appointee and can result in scientific collaborations that last throughout a career. I don't recall missing a major oceanographic conference during the two-year tenure of my IPA appointment. pointment exceeds two years, then there is a risk of estrangement from research. If the requisite time off from research or teaching activities coincides with a natural hiatus in these activities, then so much the better. It is possible to keep a research program alive and well at your home organization during the course of an IPA assignment through use of proxy PIs and diligent advance planning. Participation in extensive field activities during an appointment is likely to present difficulties; however, some involve- 
ment in data analyses and in manuscript preparation is not an unreasonable expectation. I managed, through use of proxy Principal Investigators (PIs), to maintain my own participation in one Arctic project and two Antarctic projects during my IPA. One of these actually involved fieldwork, although I did not participate, and it was possible to get some published results out.

The career stage of an IPA appointee is another primary consideration. A break from research early in a career can impede research publications and may negatively impact professional advancement within one's home organization. The impact of a temporary decrease in publication volume needs to be evaluated, though, in the context of a significantly enhanced understanding of agency workings and a broadening of acquaintances with colleagues throughout the field.

Generally, someone in mid-career will be better prepared to offer scientific advice to agency managers than someone who has just completed a Ph.D. or postdoctoral program. A late-career appointee will be able to offer lots of sage advice to an agency, but may not stand to benefit as greatly career-wise. Clearly, a spectrum of pros and cons fall in between the extremes represented by entry into an IPA appointment of a fresh post-doc and a senior university faculty member.

\section{Some Questions You Should Ask}

Assuming that you are interested in an IPA appointment, then you'll need to carry out a bit of preliminary research. First, be aware that just because an IPA appointment has not been advertised does not mean that none is available. Inquire at your agency of choice. Ask agency personnel whether you'll have any time for your own research and, if so, how much. Will the agency provide any support, such as computer time or travel funds, for this research? How much time should you expect to spend on agency-related business travel? Will you have time to continue mentoring graduate students or post-docs at your home institution? Will the agency pay for regular travel to and from your home institution? What sort of living expense allowance will the agency provide you? Policies will vary among agencies, so don't assume that the policy at one agency will apply at another.

You'll need to inquire of your home institution about substitutes for duties such as teaching. Are they amenable to your mentoring of graduate students and post-docs from a distance? Discuss with your colleagues and administrators the potential institutional benefits of your taking on an IPA. This would be the time to address any issues concerning impacts on promotions or tenure. I returned from my IPA with a tremendous amount of new insight into agency priorities and interests; the insights you gain can be of significant benefit when shared with colleagues at your own institution. This potential benefit should be pointed out to your administrators.

Finally, and most important, you need to ask yourself whether this is the right time in your career to take on an IPA, and what you will get out of it. I found my own knowledge of our national research infrastructure tremendously broadened by my experience. I was able to attend more conferences and meet more potential colleagues than would have been possible under any other circumstances. I gained inside information on agency needs and priorities that has been invaluable in project organization and in proposal preparation, and I have strengthened my own and other organizations by sharing this information. My only real regret is that I didn't take on an IPA at an earlier stage in my own career, where I would have enjoyed the benefits over a greater career span.

\section{Should I Bring My Family Along?} I found the Washington area a fascinating and enjoyable place in which to dwell. The climate is great for the roughly six months out of the year that comprise spring and autumn and requires for the remaining six months, well, some forbearance. When not traveling to the four corners of the globe on agency-related business, there are more concerts, art exhibitions, plays, sports events, street fairs and generally plain enjoyable things to do than one can reasonably take in. I spent many pleasant afternoons at the galleries and museums along the Mall, not to mention the Camden Yards home of the Baltimore Orioles. [Editor's note: The Nationals are now in town, and are an easy Metro ride away at RFK Stadium.] There are many, many superb restaurants covering most if not all nationalities. The countryside beyond the urban limits ranges in character from the wetlands of Maryland's Eastern Shore to the mountains of the Blue Ridge. It is riddled with parks and historical sites and is compellingly beautiful. Schools, especially in northern Virginia, have excellent reputations.

My own IPA was highly positive, and I think many of us can benefit from a similar experience. I hope that this account may inspire others to share in the experience. 囵 